\title{
LIGERO: AUTOMATED LIGHTNING SYSTEM WITH ANDROID APPLICATION
}

\author{
Asst. Prof. Jignyasa Sanghavi \\ Harshal Jaiswal, Akshay Wanjari, Anil Mishra, Arjit Khandelwal, Aashray Kashyap, Tanmay Agrawal, \\ Department of Computer Science and Engineering \\ Shri Ramdeobaba College of Engineering and Management, Nagpur, Maharashtra,
}

\begin{abstract}
Electricity is an important resource which is currently being used inefficiently in most of the houses and workplaces. People intentionally or unintentionally keep the lights and other electrical appliances $\mathrm{ON}$ even if no one is using it. This ephemeral condition when repeated in many places leads to a very voluminous unwanted energy loss. Moreover, smart phone controlled lights are not automated according to requirement of the person or place. To overcome this problem there is a need of automation of household electric switches. This paper introduces the idea of automated systems which will detect the presence of person in the room and accordingly appliance is switch ON like lights, fans, etc. when one enters the room and switch off or reduce the intensity of lights, fans and other electrical equipment on the absence of person in the room. Moreover, one can also control all the electrical equipment with the help of an android-app. App can be synchronized with sensors and can control the electrical switches of the equipment at their figure tips. In this paper we are proposing the hybrid approach of sensors coupled with android application which will help to overcome the problem of electrical energy losses.
\end{abstract}

Keywords - Automated lights, LDR, IoT, Relay Module, Laser Module, PIR Sensors, Automation, Android application.

\section{INTRODUCTION}

Nowadays, due to ignorance of people towards their responsibility as a human being lot of energy resources is wasted. Considering the wastage of Electricity at home and workplaces, caused due to unnecessary keeping ON appliances like Tube lights, fans, etc. even when there is no use. This gives rise to need of automating the lighting and other electrical devices according to need of the person. Also smartphones can be used to control the appliances manually. For making this some of the cases were studied such as Digital visitor counter which is used to track the count of people where the capacity of room is limited and should not exceed in rooms like seminar hall, conference hall, etc. Automatic room light and fan controller according to availability of person in the room. [1]

This paper briefs the electrical appliance automation, and achieves it using concept of Internet of Things. The aim of this project was creating an automated cloud-based server that can control the electrical appliances and prevent from wastage of energy. It also keeps the track of the units of energy consumed. This project was divided into four core modules:

- A sensor system configuration which detects the inward/outward movement of person

- Android App Development for controlling the electrical appliances

- Time scheduling module for scheduling the operation time of the appliances

- Unit history calculator for tracking consumption of Units.

\section{SENSOR SYSTEM CONFIGURATION AND DESIGN}

A. Hardware connections

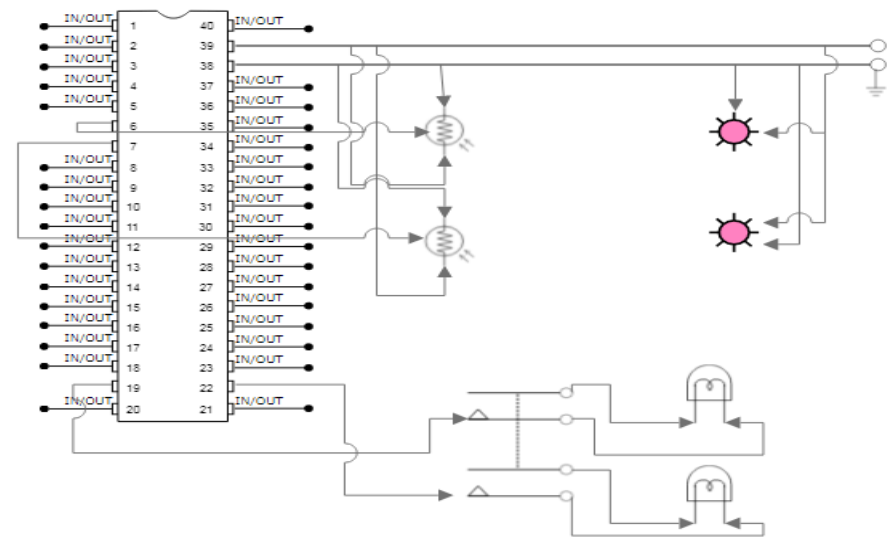

Figure 1: Connection Diagram

The Raspberry Pi 3 Model B is used for this project which is quad-core. In Raspberry pi-3 the line with the live power is connected to BCM pin 39 (GPIO 4) and ground is connected 


\section{International Journal of Engineering Applied Sciences and Technology, 2019 \\ Vol. 3, Issue 10, ISSN No. 2455-2143, Pages 47-52 \\ Published Online February 2019 in IJEAST (http://www.ijeast.com)}

to BCM 38 (GPIO 6). Two lasers and LDRs (Light Dependent Resistor) are installed on the door for detecting movement inside or outside the room. There will be two sensors installed on either sides of the entrance of the room. Laser is a semiconductor device similar to a light-emitting diode in which the laser beam is created at the diode's junction. In this project a pair of it will be continuously be focusing on LDR sensor if some person enters or exits from that room the pair of rays are cut, it determine its direction whether its entering or exiting the room. It also keeps the count of occupants in a room. Light Dependent Resistor (LDR) is a light-controlled variable resistor. The resistance of a photo-resistor decreases with increasing incident light intensity; in other words, it exhibits photoconductivity. The LDR is connected to the pi via pins 6 and 7 (GPIO 11, 13) as shown in the figure. The LDR signals the pi, whenever there is movement of a person, entering or exiting from the room. A relay module is attached with gets signals from pi via pins 19, 22 (GPIO 37, 38) which controls the electrical appliances. Maximum support for one pi is 24 appliances. The basic idea of the module is to automate the electrical appliances without changing the current system.

\section{B. Prototype-}

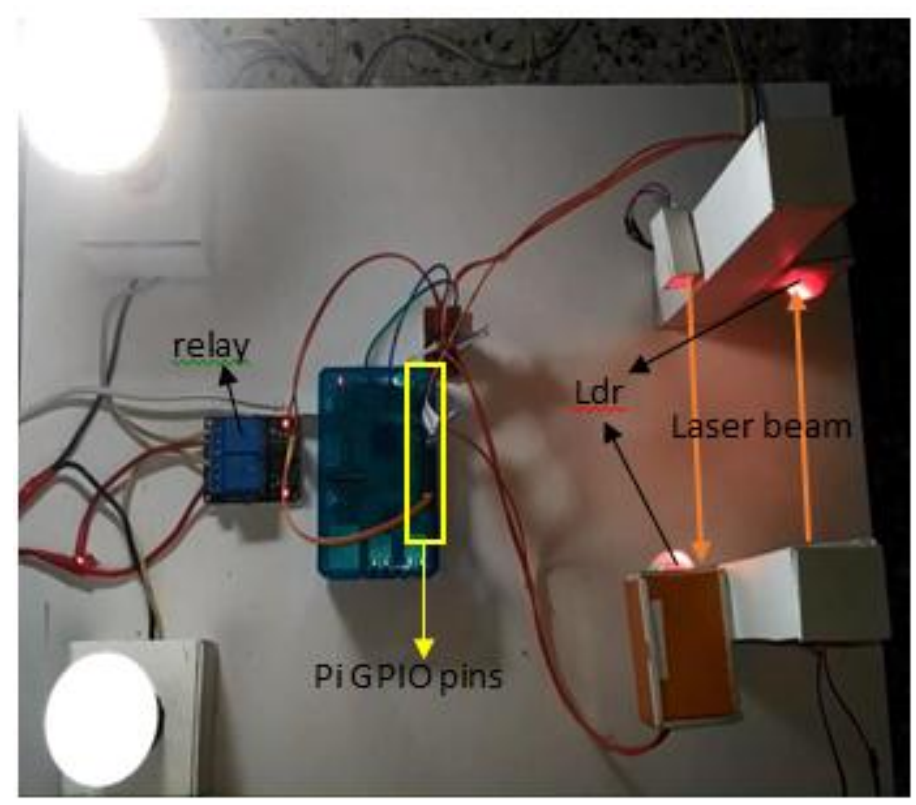

Figure 2: Design Prototype

The figure 2 shows the design prototype of the project. The LDRs with lasers are installed on the doors to the right side. These sensors are connected with Raspberry Pi3 so that they can signal to server if some movement detected. Relay Module is connected to $\mathrm{Pi}$ and the electrical Appliance. The more electrical appliances can be added by incrementing the number of relay Modules. The RasberryPi is also responsible for calculating energy consumption, time scheduling of the appliance and synchronization with Android App.

\section{ANDROID APP DEVELOPMENT}

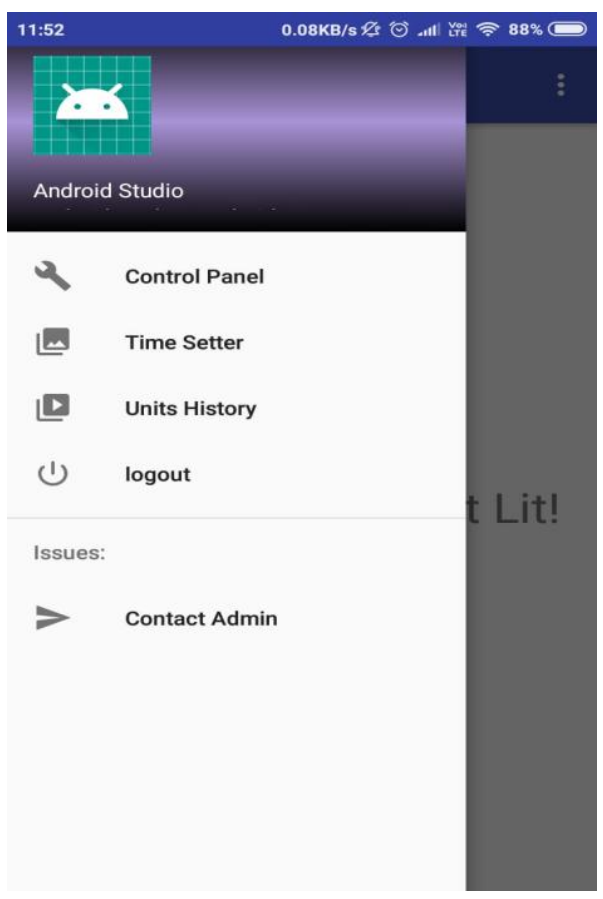

Figure 3: Main page of App

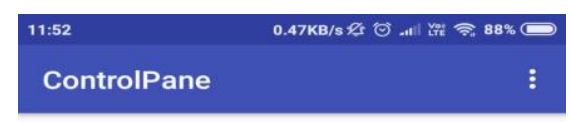

\section{Room1}

\section{light1 \\ light2}

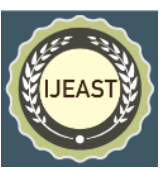

(1) 
1. Control Panel: This page has toggle switches (figure4) to control appliances from anywhere. These switches are coupled with firebase real time database, denoting altered changes on every android devices as well as raspberry-pi.

2. Time Setter: This module enable user to set turn on and turn off time of particular appliance.

3. Unit History: This module gives history of the units consumed by any appliances in watt.

\section{TIME SCHEDULING MODULE FOR SCHEDULING THE OPERATION TIME OF THE APPLIANCES}

One of the major module of this project is scheduling the appliances and controlling them accordingly. This module can help save energy of parking lights, home entrance lights, corridor lights, staircase lights which are generally ON even when not required

\section{Device Scheduler}

device1
device2
device3
device4
device5

Figure 5: Device Scheduler

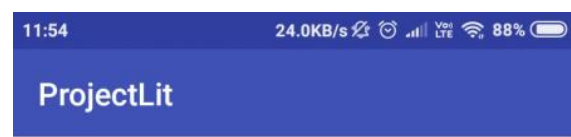

\section{Device Scheduler}

device1

Start-time 18:15

End-time 22:35

SAVE

Figure 6 : Setting Device1 Schedule

User can select any of appliance in the list as shown in figure 5. A user can then set the turn ON and OFF time of that particular appliance. This novel feature minimises the use of particular lights as well as help user to manage all such kinds of appliances at a tip of finger. A User can hence reduce its bills on electric because lights in parking,etc accounts for a huge energy loss in many societies and buildings.

\section{UNIT HISTORY CALCULATOR FOR TRACKING} CONSUMPTION OF UNITS.

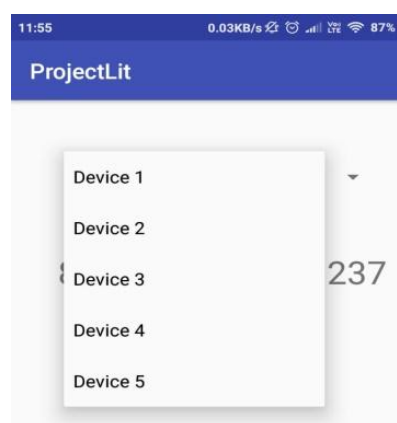


International Journal of Engineering Applied Sciences and Technology, 2019

Vol. 3, Issue 10, ISSN No. 2455-2143, Pages 47-52

Published Online February 2019 in IJEAST (http://www.ijeast.com)

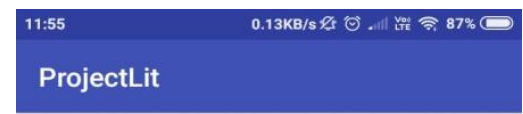

Device 2

4.690664897977018
Figure 8: Device 2Unit history

Another novel and important feature of this project is unit history calculator. This module gives a report of unit consumed by different appliances and helps user determine over usage of energy by any appliance. User have to input the watt consumption associated with the appliance at the time of signing in. The usage is simply calculated by the product of the watt consumed by the appliance and the time it was being turned on. This feature can help in monitoring the unwanted energy wastage by individual appliance.

\section{WORKING OF PROJECT}

\section{A. Sensor configuration}

The first module is about sensor configuration. Two laser and sensor pairs are installed on the door of Prototype. If the outer pair is intercepted first and then inner pair is intercepted it implies that someone has entered the room or inward movement has taken place. If inner pair is intercepted first and then outer pair is intercepted it implies that someone has exited from the room or outward movement has taken place. With every inward movement the count variable in the firebase database will be incremented and correspondingly with outward movement the count will be decremented. Depending upon the order in which the sensor senses (i.e. a person is entering or exiting the room); it will register the incoming or outgoing person and sends signal to server. As soon as a person enters the room, the sensor will detect the movement and switch ON the electrical Appliance configured. Similarly, the sensor notifies the server when a person leaves the room and Switch OFF the appliance. The count of person inside the room is maintained.

\section{B. Android App}

Android app used in this project was created and designed with the tool Android Studio.

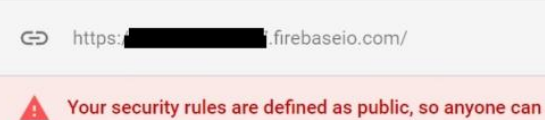

A Your security rules are defined as public, so anyone can

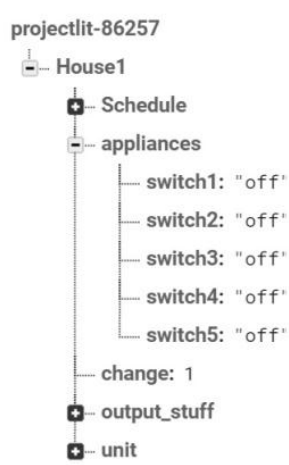

Figure 9 : Firebase Console

\begin{tabular}{|c|c|}
\hline 11:52 & 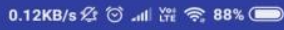 \\
\hline ControlPane & $\vdots$ \\
\hline
\end{tabular}

Room1

\section{light1}

\section{light2}

Figure 10: Control Panel with Light1 ON

Using android app user can switch ON and OFF the appliances. The app in the project uses firebase real time database that manages real time data change in all android device. Firebase is also continuously monitored by the raspberry pi to mark any change in the state by android device. The firebase structure shown in figure 9 is used in this project. 


\section{International Journal of Engineering Applied Sciences and Technology, 2019 \\ Vol. 3, Issue 10, ISSN No. 2455-2143, Pages 47-52 \\ Published Online February 2019 in IJEAST (http://www.ijeast.com)}

Initially all the appliances are turned off and when user turn $\mathrm{ON}$ any appliance as shown in figure 10 the value of the particular switch changes to on denoted in figure 11 .

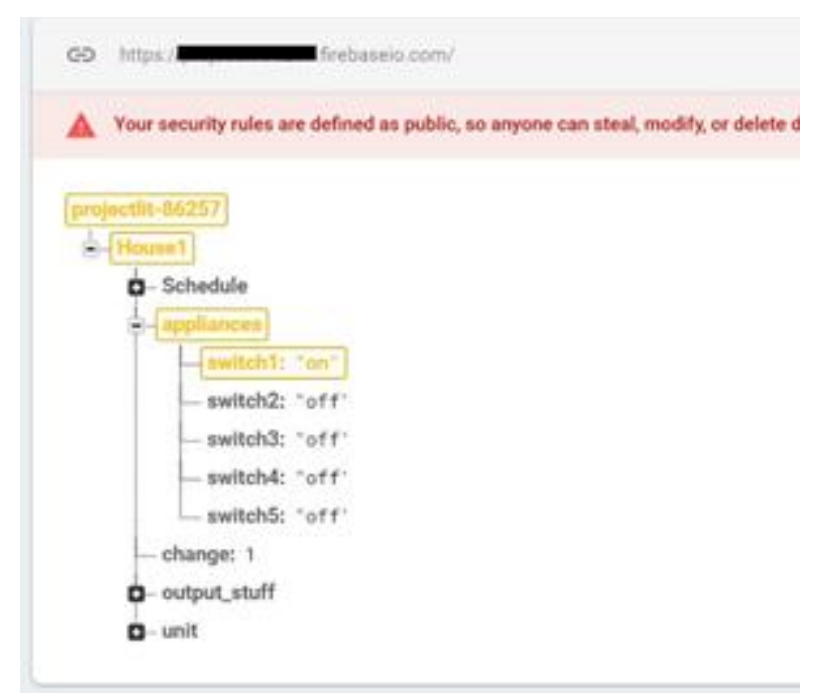

Figure 11: Firebase Console with switch1 ON

\section{Scheduling of Appliance}

This module also works on the firebase real time database. When user set a specific time to turn ON and OFF the appliance as in figure 6 , the information is updated in the database figure 12 . The raspberry-pi monitors its clock time and trigger $\mathrm{ON}$ or OFF the appliance accordingly. The clock in the pi is updated with internet so the time remains accurate. Moreover, irrespective of android device this module can work when once set. So there is no need to turn ON or OFF lights of parking, etc. Instead they will work on themselves as per the time set by the user.

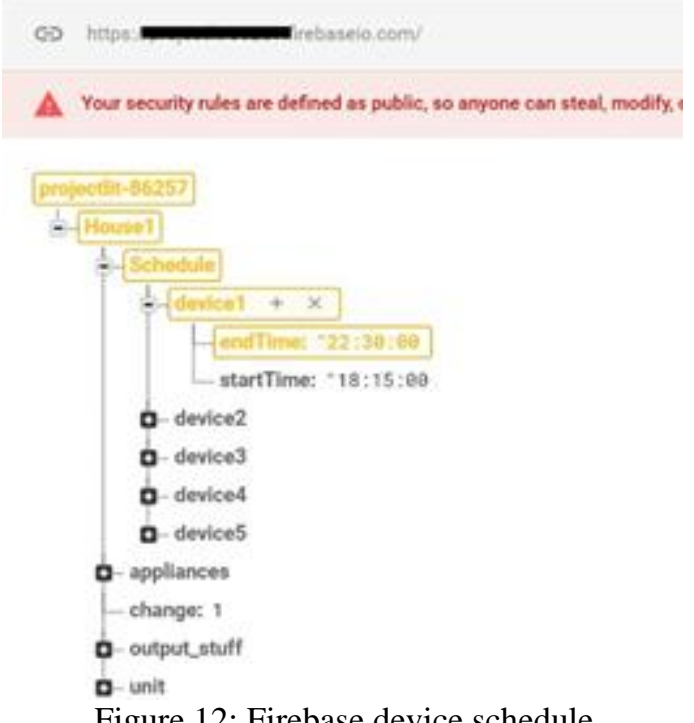

Figure 12: Firebase device schedule

\section{Unit consumption Calculator}

Unlike above module where android device manipulates the firebase in this module the raspberry pi calculates and update the unit history of the appliance. The time at which device is turned on is noted and subtracted from the time when it is turned off. The resultant difference gives the time for which the appliance was turned on and its product with the watt of appliance gives you the approximate unit consumption of particular devices.

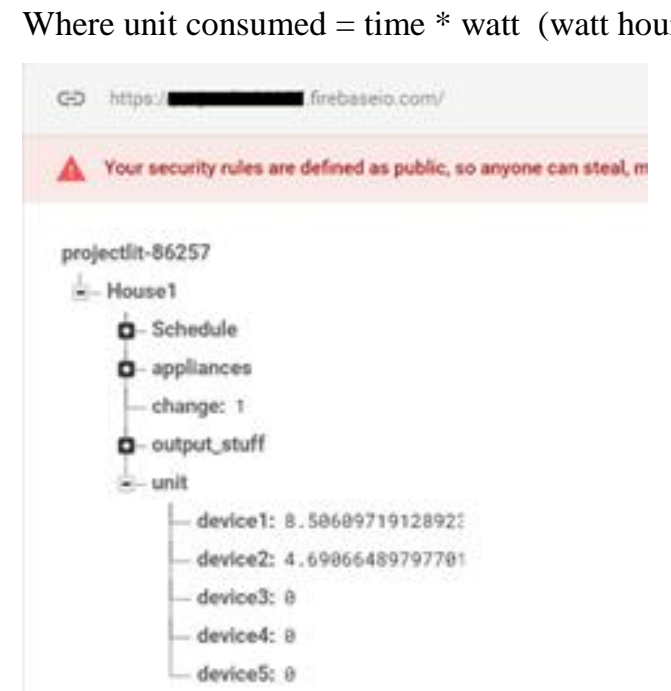

Figure 13: Firebase unit history.

\section{Simulation RESUlTS:}

This project was tested under rigorous conditions with less internet connectivity, time lag in server connections, etc. A sample of 10 such cases is shown below; it is found that there average lag of 2.18 seconds in normal internet speed, in worst case it is less than $3.5 \mathrm{sec}$.

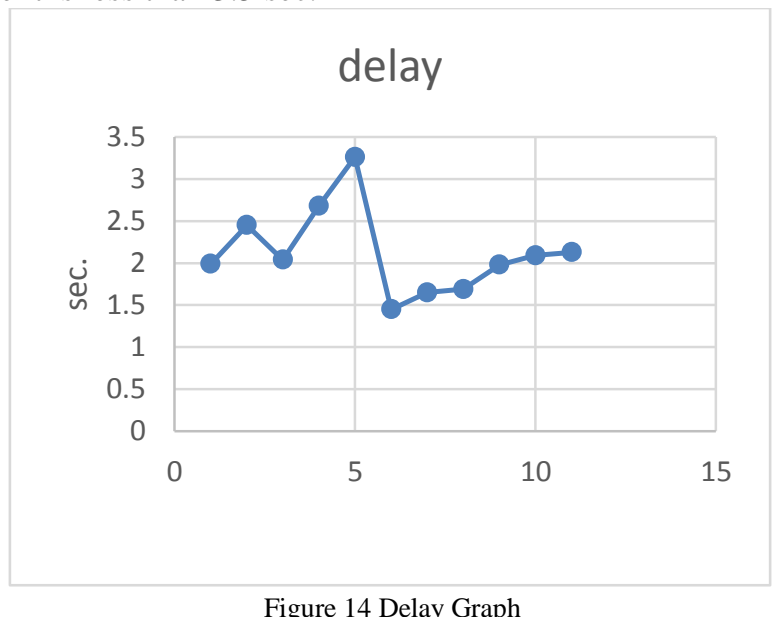

Figure 14 Delay Graph 


\begin{tabular}{|c|c|}
\hline Case Number & Delay in Connecting (Sec) \\
\hline 1 & 1.99 \\
\hline 2 & 2.45 \\
\hline 3 & 2.04 \\
\hline 4 & 2.68 \\
\hline 5 & 3.26 \\
\hline 6 & 1.45 \\
\hline 7 & 1.65 \\
\hline 8 & 1.69 \\
\hline 9 & 1.98 \\
\hline 10 & 2.09 \\
\hline Average & $\mathbf{2 . 1 2}$ \\
\hline
\end{tabular}

Table1 Delay Table

The figure 14 shows the delay while acquiring connection with server and then performing action. The delay values are in seconds which are nominal compared to losses which are occurring today. One can also control the electrical appliances using android app which will override the control of appliances through hardware.

\section{CONCLUSION:}

As the world is moving towards smart technological paradigms it's important that the existing architecture must be replaced by the innovations of modern world. But economic condition of the target audience plays very vital role for making that shift. Any innovation is welcomed if it's simplified as well as economical. With this as a principle behind development this system has worked to make LIGERO a reality. By using Automated Lightning system, one can prevent wastage of electrical energy. Android app can comfort people with controlling the devices on their figure tips. Statistics regarding the energy consumption in android app can help to analyze the consumption and thus controlling unwanted electricity wastage of an individual.

\section{REFERENCES:}

[1] Yuganandhine.R.R ,J. Kiruthika , S. Manju ,K. Mythili , Manikandan.R.K , K. Mythili.(2017) in Automatic Room light and fan controller with bidirectional visitor counter in International Journal of Recent Trends in Engineering \& Research (IJRTER) Conference on Electronics, Information and Communication Systems (CELICS'17) Special Issue; (DOI10.23883/IJRTER.CONF.20170331.005.20BU $\mathrm{K})$

[2] Last accessed $04 \quad$ February 2019 https://www.zdnet.com/article/what-is-the-raspberry- pi-3-everything-you-need-to-know-about-the-tinylow-cost-computer/

[3] Tripathi Ankita, Gupta Ila, Mishra Kshama, Singh Shipra (2014) Automatic room light controller with visitor counter, last accessed 04 February 2019 http://www.academia.edu/7206198/a_project_report

[4] Syeda Puspita Mouri1, Syed Nazmus Sakib, Zannatul Ferdous, Md. Abu Taher, (2015) Automatic lighting and security system design using PIRMotion sensor, Journal of Institute of Information Technology, Jahangirnagar University(Vol. 14, no. 8, pp. 1-5).

[5] SharathPatil G.S, Rudresh S. M, Kallendrachari.K. Vani. H.V(2015)- Design and Implementation of Automatic Street Light Control Using Sensors and Solar Panel, International Journal of Engineeing Research and Applications(vol. 5, no. 6, pp. 97-100).

[6] Abdul Latif Saleem, Sagar Raj. R, Datta Sachin N. S, MS Usha(2015)- Street Light Monitoring and Control System, International Journal of Engineering and Control System,(vol. 1, no. 2, pp. 68-71).

[7] Rajpu K.Y., Khatav G., Pujari M., Yadav P.(2013) Intelligent Street Lighting Sytem using GSM, International Journal of Enginnering Science Invention(vol. 2, no. 3, pp. 60-69)

[8] Srivastava S.(2013)- Automatic Street Lights," Advance in Electronic and Electric Engineering, (vol. 3, no. 5, pp. 539- 342).

[9] Changseok Bae, Jinho Yoo, Kyuchang Kang, Yoonsik Choe, and Jeunwoo Lee(2003)-Home server for home digital service environments, Proceedings of IEEE International Conference on Consumer Electronics(vol 49, pp. 1129-1135).

[10] Alkar A. Z., and Buhur U.(2005)-An Internet Based Wireless Home Automation System for Multifunctional Devices, IEEE Transactions on Consumer Electronics,(vol. 51, no. 4, pp. 11691174).

[11] Yu-Ping Tsou, Jun-Wei Hsieh, Cheng-Ting Lin, and Chun-Yu Chen(20060 -Building a Remote Supervisory Control Network System for Smart Home Applications, Proceeding of IEEE International Conference on Systems, Man and Cybernetics(ICSMC '06, vol. 3, pp. 1826-1830).

[12] Al-Ali A. R. and Al-Rousan M.(2004) "Java-based home automation system," IEEE Transactions on Consumer Electronics(vol. 50, no. 2, pp.498-504). 